\title{
ANÁLISE QUÍMICA DO PECÍOLO E LIMBO FOLIAR COMO INDICADORA DO ESTADO NUTRICIONAL DOS MAMOEIROS 'SOLO' E 'FORMOSA'
}

\author{
Cláudia Sales Marinho²*; Pedro Henrique Monnerat²; Almy Jr. Cordeiro de Carvalho²; Sérgio \\ Lúcio David Marins²; Alcílio Vieira ${ }^{3}$ \\ ${ }^{2}$ Centro de Ciências e Tecnologias Agropecuárias - UENF/CCTA/LFIT - Av. Alberto Lamego, 2000 - Horto - \\ CEP: 28015620 - Campos dos Goytacazes, RJ. \\ ${ }^{3}$ Estação Experimental da PESAGRO-Rio/Macaé - Estrada Velha de Glicério, Km 3 - CEP: 27901-970 - Macaé, RJ. \\ *Autor correspondente <marinho@uenf.br>
}

RESUMO: A ausência de um consenso na literatura sobre qual parte da folha, limbo ou pecíolo, seria a mais indicada para avaliação do estado nutricional do mamoeiro, dificulta o uso da análise foliar como ferramenta de diagnose para a cultura. Assim, foi conduzido um experimento para comparar a diagnose do estado nutricional efetuada pela análise do limbo e do pecíolo foliar de mamoeiros pertencentes aos grupos 'Solo' e 'Formosa'. Foi adotado o delineamento em blocos casualizados para avaliar seis variedades de mamoeiros, três de cada grupo. Foram retiradas amostras foliares em cinco épocas, a cada três meses. A folha recémmadura foi dividida em limbo e pecíolo, onde foram determinados os teores de $\mathrm{N}_{1} \mathrm{NO}_{3}{ }^{-}, \mathrm{P}, \mathrm{K}, \mathrm{Ca}, \mathrm{Mg}, \mathrm{S}, \mathrm{B}, \mathrm{Cl}$, $\mathrm{Fe}, \mathrm{Mn}$ e $\mathrm{Zn}$. Estes teores foram comparados com os citados na literatura como adequados para a cultura. A diagnose do estado nutricional do mamoeiro quando efetuada por meio da análise do limbo ou do pecíolo foliar levou a diferentes diagnósticos mostrando a necessidade de definição de um único padrão. A análise do limbo foliar mostrou-se mais efetiva que a do pecíolo para diagnosticar o estado nutricional, diferenciando melhor as variedades de mamoeiro, em relação a N, $\mathrm{P}, \mathrm{Ke} \mathrm{Cl}$, não diferindo em relação aos demais nutrientes. Sendo assim, o limbo foliar deve ser utilizado como indicador do estado nutricional do mamoeiro.

Palavras-chave: Carica papaya, variedade, análise foliar, macro e micronutrientes

\section{PETIOLE AND LEAF BLADE ANALYSES AS NUTRITIONAL STATUS INDICATORS OF 'SOLO' AND 'FORMOSA' PAPAYA TREES}

\begin{abstract}
The absence of a literature consensus about parts of leaves, blade or petiole which would be most indicative of the nutritional status of papaya trees, has hindered the use of foliar analysis as a diagnosis tool for this crop. An experiment was carried out to compare the nutricional status evaluated using blades and petioles of 'solo' and 'formosa' papaya groups. A completely randomized block design was used to test six varieties, three of each group. Leaves were sampled every three months in five occasions. Recently matured leaves were separated in petioles and blades for the evaluation of $\mathrm{N}_{1} \mathrm{NO}_{3}, \mathrm{P}, \mathrm{K}, \mathrm{Ca}, \mathrm{Mg}, \mathrm{S}, \mathrm{B}, \mathrm{Cl}, \mathrm{Fe}, \mathrm{Mn}$ and $\mathrm{Zn}$ concentrations. These concentrations were compared to those reported in the literature for this crop. The nutritional status diagnosis of the papaya plants, when made by means of blade or petiole leaves, led to different diagnoses showing the need of the definition of a single pattern. Blade has shown to be more effective than petiole for the diagnosis of the nutritional status, better differentiating the papaya tree varieties in relation to $\mathrm{N}, \mathrm{P}, \mathrm{K}$ and $\mathrm{Cl}$, and not differing in relation to the other nutrients. It is here recommended to use the blade as indicator of the nutritional status of papaya plants.

Key words: Carica papaya, variety, leaves analysis, macronutrients
\end{abstract}

\section{INTRODUÇÃO}

O uso da análise foliar, na diagnose do estado nutricional das plantas, baseia-se no fato de existir uma correlação entre sua taxa de crescimento ou de produção e o teor de nutrientes nos seus tecidos (Benton Jones et al., 1990). Dessa correlação são estabelecidos pontos limites dos teores de nutrientes, correspondentes às mudanças na resposta das plantas em termos de produção. Tais teores são considerados "níveis críticos" e delimitam faixas de teores relacionados às deficiências nutricionais, aos níveis adequados ou à toxidez de minerais.
A aplicação do método do nível crítico foliar para diagnose do estado nutricional do mamoeiro depara-se com alguns problemas, sendo um deles a ausência de um consenso sobre qual parte da folha seria a mais adequada para o processo de diagnose. Muitos pesquisadores têm comparado a sensibilidade do limbo e do pecíolo, para detectar a disponibilidade de nutrientes para o mamoeiro encontrando resultados variáveis. O pecíolo é a parte preferida, em alguns casos, particularmente quando se deseja determinar uma fração solúvel do nutriente.

Alguns autores recomendam a análise do pecíolo na avaliação do "status" de N (Awada, 1969), de P

Parte da Tese de Doutorado da primeira autora, apresentada à UENF - Campos dos Goytacazes, RJ.

Scientia Agricola, v.59, n.2, p.373-381, abr./jun. 2002 
(Awada \& Long, 1969), de K (Awada \& Long, 1971b) e de B (Pérez \& Childers 1982). Entretanto, não existe unanimidade na literatura sobre qual parte da folha seria a mais adequada. Prezzoti (1992) e Viégas (1997) verificaram maior sensibilidade do limbo foliar para detectar a disponibilidade de $\mathrm{N}$ para as plantas. Pérez \& Childers (1982), observaram que o limbo foliar, também, foi mais sensível como indicador do nível de $\mathrm{Mn}$ no mamoeiro.

O objetivo desse trabalho foi avaliar o estado nutricional de mamoeiros, dos grupos 'Solo' e 'Formosa', e comparar a utilização do limbo e do pecíolo foliar no processo de diagnose.

\section{MATERIAL E MÉTODOS}

\section{O experimento foi conduzido na Estação}

Experimental de Fruticultura da PESAGRO-Rio, em Macaé-RJ sobre um Argissolo Amarelo distrófico, no período de novembro de 1995 a março de 1997. A estação encontra-se a uma altitude de 4 metros, latitude de $22^{\circ} 24^{\prime} 58^{\prime \prime}$ e longitude de $41^{\circ} 42^{\prime} 30^{\prime \prime}$. Apresenta temperatura média máxima de $28^{\circ} \mathrm{C}$, média mínima de $19,5^{\circ} \mathrm{C}$, precipitação pluviométrica de $1244 \mathrm{~mm}$ anuais e umidade relativa de $81,1 \%$.

As mudas foram produzidas sob ripado, em sacos de polietileno preto $(23 \times 12 \mathrm{~cm})$, preenchidos com substrato constituído de terra arenosa e esterco de curral curtido, na proporção de 3:1. Ao substrato foi adicionado, ainda, superfosfato simples e cloreto de potássio, nas doses de 2,5 e $1 \mathrm{~kg} \mathrm{~m}^{-3}$ de substrato, respectivamente.

As mudas foram transferidas para a área experimental quando atingiram a altura de $20 \mathrm{~cm}$. $O$ plantio foi efetuado em fileiras duplas no espaçamento de 3,6 m entre linhas duplas e 2,0 m entre linhas simples e entre plantas.

A aração, a aplicação do calcário $\left(1 \mathrm{t} \mathrm{ha}{ }^{-1}\right)$ e a gradagem foram realizadas 60 dias antes do transplantio. Foram plantadas três mudas por cova e após o desbaste, efetuado após a sexagem das plantas, aos quatro meses após o transplantio, deixou-se uma planta hermafrodita por cova.

Foram aplicados, na cova de plantio, $15 \mathrm{~L}$ de esterco de curral curtido, $200 \mathrm{~g}$ de calcário dolomítico, $400 \mathrm{~g}$ de superfosfato simples, $50 \mathrm{~g}$ de cloreto de potássio e $20 \mathrm{~g}$ da formulação comercial FTE BR 12 $\left(\mathrm{B}=18 ; \mathrm{Cu}=8 ; \mathrm{Fe}=30 ; \mathrm{Mn}=30 ; \mathrm{Mo}=1\right.$ e $\left.\mathrm{Zn}=90 \mathrm{~g} \mathrm{~kg}^{-1}\right)$

$\mathrm{O}$ delineamento experimental adotado foi o de blocos casualizados com seis tratamentos e três repetições. Os tratamentos foram constituídos por três variedades de mamoeiros pertencentes ao grupo solo 'Sunrise Solo 72/12-SD/ES' (SS 72/12); 'Sunrise SoloSD/ES' (SS); 'Santa Bárbara' (SB), e três pertencentes ao grupo formosa - 'Tainung 01/781' (T1); 'Tainung 02/ 785' (T2) e 'Know-You 01/784' ( KY).

A parcela experimental, com as dimensões de 5,6 $\times$ 4,0 m, foi composta por 4 plantas hermafroditas.
As adubações de cobertura foram efetuadas conforme as recomendações de Marin et al. (1995). Nos meses ímpares foram aplicados $70 \mathrm{~g}$ de sulfato de amônio e $34 \mathrm{~g}$ de cloreto de potássio e nos meses pares, $40 \mathrm{~g}$ de sulfato de amônio, $40 \mathrm{~g}$ de superfosfato simples e $20 \mathrm{~g}$ de cloreto de potássio. Uma vez que, seguindo essas recomendações, as plantas apresentaram sintomas de deficiência de nitrogênio, o que foi confirmado pela primeira análise foliar, a partir do $5^{\circ}$ mês, passou-se a aplicar o dobro do sulfato de amônio e do cloreto de potássio dessa recomendação. Essas adubações foram efetuadas na projeção da copa, a 20 $\mathrm{cm}$ do caule, e o adubo levemente incorporado com uma enxada. A análise química das amostras de solo da área experimental, realizadas de acordo com a metodologia descrita pela Embrapa (1979) (Tabela 1).A partir de dezembro de 1996 a estação meteorológica foi desativada e os dados climáticos locais não puderam mais ser registrados (Figura 1 ).

A área foi irrigada por um sistema de aspersão sobre copa e o manejo da água baseou-se, no ano de 1996, nas observações climáticas, registradas em uma estação agrometeorológica, localizada a $500 \mathrm{~m}$ da área experimental, no teor de umidade do solo, e na fase de crescimento e desenvolvimento da cultura. Em 1997, para o manejo da irrigação, foram utilizados apenas o teor de umidade do solo e a fase de desenvolvimento da cultura.

Foram retiradas amostras foliares em cinco épocas, com intervalos trimestrais, sendo a primeira realizada logo após a sexagem das plantas, no $4^{\circ}$ mês após o transplantio.

Tabela 1 - Características químicas de amostras de solo da área antes da instalação do experimento.

\begin{tabular}{|c|c|c|}
\hline & \multicolumn{2}{|c|}{ Profundidade } \\
\hline & $0-20$ & $20-40$ \\
\hline & \multicolumn{2}{|c|}{ - } \\
\hline $\mathrm{pH}$ em água & 5,3 & 4,8 \\
\hline $\mathrm{Ca}^{2+}\left(\mathrm{mmol}_{\mathrm{c}} \mathrm{dm}^{-3}\right)$ & 14 & 8 \\
\hline $\mathrm{Mg}^{2+}\left(\mathrm{mmol}_{\mathrm{c}} \mathrm{dm}^{-3}\right)$ & 5 & 4 \\
\hline$P\left(\mathrm{mg} \mathrm{dm}^{-3}\right)$ & 2,6 & 5,9 \\
\hline $\mathrm{K}^{+}\left(\mathrm{mmol}_{\mathrm{c}} \mathrm{dm}^{-3}\right)$ & 0,6 & 0,5 \\
\hline $\left.\mathrm{Al}^{3+}\left(\mathrm{mmol}_{\mathrm{c}} \mathrm{dm}^{-3}\right)\right)$ & 0,5 & 5,1 \\
\hline $\mathrm{H}+\mathrm{Al}\left(\mathrm{mmol}_{\mathrm{c}} \mathrm{dm}^{-3}\right)$ & 5,8 & 15 \\
\hline $\mathrm{MO}\left(\mathrm{g} \mathrm{kg}^{-1}\right)$ & 5 & - \\
\hline $\mathrm{SB}\left(\mathrm{mmol}_{\mathrm{c}} \mathrm{dm}^{-3}\right)$ & 19,6 & 12,5 \\
\hline CTC efetiva $\left(\mathrm{mmol}_{\mathrm{c}} \mathrm{dm}^{-3}\right)$ & 20,1 & 17,6 \\
\hline $\mathrm{m}(\%)$ & 2,5 & 28,9 \\
\hline CTC potencial $\left(\mathrm{mmol}_{\mathrm{c}} \mathrm{dm}^{-3}\right)$ & 25,4 & 27,5 \\
\hline $\mathrm{V}(\%)$ & 77 & 45 \\
\hline $\mathrm{CE}\left(\mathrm{dS} \mathrm{m}^{-1} / 25^{\circ} \mathrm{C}\right)$ & 0,09 & \\
\hline
\end{tabular}

Local de Análise: Laboratório de Análises de Solo da Fundenor, Campos dos Goytacazes-RJ. 


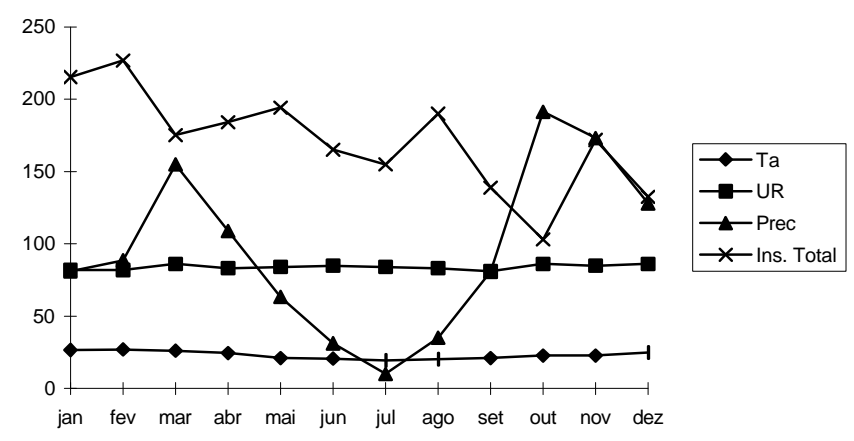

Figura 1 - Médias mensais de Temperatura $\left(\mathrm{Ta}-{ }^{\circ} \mathrm{C}\right)$, umidade relativa (UR - \%), precipitação (Prec - mm) e Insolação Total (Ins. Total - h) observadas durante o ano de 1996. Estação Experimental de Macaé-RJ.

A folhas coletada para análise de nutrientes foi a recém-madura, caracterizada por apresentar uma flor recém-aberta em sua axila. As coletas de folhas, duas por parcela, foram efetuadas sempre entre $9 \mathrm{~h} 00$ e $11 \mathrm{~h} 00$.

Imediatamente após o corte, as folhas foram separadas em limbo e pecíolo, secas em estufa de circulação forçada de ar, à temperatura de $70{ }^{\circ} \mathrm{C}$ por 48 horas e trituradas em moinho (tipo Wiley) com peneira de 20 "mesh". A matéria seca, assim obtida, foi submetida às análises químicas. As análises foram realizadas de acordo com metodologias descritas por Malavolta et al. (1997) e Jones Jr. et al. (1991).

$\mathrm{O} \mathrm{N}$ foi determinado pelo método de Nessler, após digestão da matéria seca com $\mathrm{H}_{2} \mathrm{SO}_{4}$ e $\mathrm{H}_{2} \mathrm{O}_{2}$. O $\mathrm{NO}_{3}{ }^{-}$após extração em água, em banho Maria por uma hora, foi determinado pelo método de ultravioleta. No extrato, assim obtido, determinou-se, também, o cloreto por titulação com $\mathrm{AgNO}_{3}$

As aplicações constantes de fungicidas cúpricos impediram a determinação precisa do $\mathrm{Cu}$, sendo o mesmo excluído das análises.

Os frutos foram colhidos e pesados, semanalmente, entre junho de 1996 a fevereiro de 1997. A produção de frutos foi agrupada em três períodos de três meses, junho a agosto/96; setembro a novembro/ 96 e dezembro a fevereiro/97.

Para as análises químicas os frutos foram amostrados em janeiro de 1997, quando apresentavam a casca verde claro e com duas estrias amareladas longitudinais, partindo da base do fruto até o pedúnculo. Este ponto de colheita, é o mais utilizado para o mercado interno e externo (Souza, 1998). Nesta ocasião, foram amostrados cinco frutos por variedade nos quais foram determinados $\mathrm{opH}$, os sólidos solúveis totais (SST), a acidez total titulável (ATT) e o ácido ascórbico (Vit. C). As análises foram efetuadas na polpa triturada por um liquidificador doméstico, marca Arno, modelo LE, por 30 segundos na velocidade " 3 ", sem a casca e sem as sementes. $\mathrm{O} \mathrm{pH}$ foi determinado por meio de leitura direta. A acidez total titulável, expressa em g de ácido cítrico por $100 \mathrm{~g}$ de polpa, foi determinada a partir de uma alíquota de $5 \mathrm{~mL}$ da polpa centrifugada, usando-se o indicador fenolftaleína, seguido por titulação com $\mathrm{NaOH}$ $0,1 \mathrm{~mol} \mathrm{~L}^{-1}$. A vitamina $C$, expressa em $\mathrm{mg}$ de ácido ascórbico por $100 \mathrm{~g}$ de polpa, foi obtida por meio da titulação com 2,6 dinitrofenilhidrazina (2,6 D).

Os dados foram submetidos a análises de variâncias e as médias dos tratamentos comparadas pelo teste Tukey (5\%). Os teores de nutrientes nas folhas foram analisados como parcelas subdivididas no tempo e comparados com níveis críticos ou teores adequados apresentados por Awada \& Long (1971a, 1978, 1980), Awada (1977), Perez \& Childers (1982), Perez-Lopez \& Reyes (1984) e Reuther \& Robinson (1986), para o pecíolo e com os apresentados por Prezzoti (1992), Costa (1995) e Viégas (1997), para o limbo.

$\mathrm{Na}$ ausência de interação entre os fatores optouse por apresentar as médias gerais dos teores de nutrientes, em cada época, englobando todas as variedades. Quando houve interação foi feito o desdobramento dos teores médios, para cada variedade, em cada época de amostragem.

\section{RESULTADOS E DISCUSSÃO}

A produção das variedades do grupo Solo aproximou-se daquelas obtidas por diversos autores para diferentes regiões (Luna, 1986; Viegas, 1997), ficando, entretanto, abaixo da produção das lavouras consideradas por Costa (1995) como de alta produtividade no Espírito Santo (acima de $50 \mathrm{t} \mathrm{ha}^{-1}$ ) (Tabela 2). Segundo Luna (1986), o tamanho médio e características dos frutos apresentaram-se dentro dos padrões das variedades (Tabela 3).

No pecíolo, os teores de $\mathrm{N}$ e $\mathrm{NO}_{3}^{-}$não apresentaram diferenças significativas entre as variedades. Variações são observadas apenas entre as épocas de amostragem, sem, entretanto, seguirem a mesma tendência para as duas formas de N (Figura 2).

Alguns autores recomendam a utilização de testes rápidos em pecíolos, onde o teor de $\mathrm{NO}_{3}{ }^{-}$ encontrado é utilizado para inferências sobre a disponibilidade de N para a planta (Waterer, 1997). Neste caso, não foi observada uma correspondência entre o teor de $\mathrm{NO}_{3}{ }^{-}$e o de teor de $\mathrm{N}$-total. Além disso, os teores de $\mathrm{NO}_{3}$ no limbo aumentaram entre as amostragens efetuadas em março e junho em correspondência ao aumento da taxa de adubação efetuada entre essas épocas, o que não foi observado no pecíolo. Estes resultados contrariam uma unanimidade na literatura de que o pecíolo seria o mais indicado para determinação de frações solúveis do que o limbo foliar. No caso do mamoeiro estes resultados podem ser decorrentes da existência de uma grande quantidade de nervuras no limbo foliar. Os teores médios de $\mathrm{NO}_{3}{ }^{-}$corresponderam a $14,2 \%$ do N-total no pecíolo e $3,2 \%$ no limbo.

$\mathrm{Na}$ primeira amostragem efetuada em mar/96, constatou-se que os teores de $\mathrm{N}$-total, no pecíolo e no limbo, encontravam-se muito abaixo dos níveis críticos 
Tabela 2 - Produtividade média, das variedades de mamoeiro, agrupada em três diferentes períodos. PESAGRO-Rio, Macaé - RJ.

\begin{tabular}{lcccc}
\hline \multirow{2}{*}{ Variedade } & \multicolumn{3}{c}{ Época } & \multirow{2}{*}{ Total } \\
\cline { 2 - 3 } & Jun./jul./ago. & Set./out./nov. & Dez./jan./fev. & \\
\hline SS 72/12 & $10,5 \mathrm{Ba}$ & $14,0 \mathrm{Ba}$ & $14,5 \mathrm{Ba}$ & $39,0 \mathrm{AB}$ \\
SS & $8,8 \mathrm{Ba}$ & $15,0 \mathrm{Ba}$ & $11,2 \mathrm{Ba}$ & $35,0 \mathrm{~B}$ \\
$\mathrm{SB}$ & $9,6 \mathrm{Ba}$ & $12,0 \mathrm{Ba}$ & $11,7 \mathrm{Ba}$ & $33,3 \mathrm{~B}$ \\
T1 & $15,0 \mathrm{ABb}$ & $27,0 \mathrm{Aa}$ & $24,0 \mathrm{Aa}$ & $65,8 \mathrm{~A}$ \\
T2 & $22,4 \mathrm{Aa}$ & $13,7 \mathrm{Bb}$ & $7,6 \mathrm{Bb}$ & $43,7 \mathrm{AB}$ \\
KY & $20,2 \mathrm{Ab}$ & $30,7 \mathrm{Aa}$ & $13,5 \mathrm{Bb}$ & $64,4 \mathrm{~A}$ \\
\hline
\end{tabular}

Letras minúsculas comparam médias entre períodos e maiúsculas entre variedades (teste Tukey a $5 \%$ )

Tabela 3 - Características físicas e químicas dos frutos das variedades de mamoeiros colhidos em janeiro de 1996. PESAGRO-Rio, Macaé - RJ.

\begin{tabular}{lcccccc}
\hline & \multicolumn{7}{c}{ Variedade } \\
\cline { 2 - 7 } & $\mathrm{SS} / 7212$ & $\mathrm{SS}$ & $\mathrm{SB}$ & $\mathrm{T} 1$ & $\mathrm{~T} 2$ & $\mathrm{KY}$ \\
\hline Peso $(\mathrm{g})$ & 466 & 599 & 508 & 1354 & 1112 & 2010 \\
Comprimento $(\mathrm{cm})$ & 13,5 & 14,2 & 15,3 & 22,3 & 22,4 & 28,1 \\
Diâmetro $(\mathrm{cm})$ & 8,44 & 9,82 & 8,67 & 11,66 & 10,72 & 12,55 \\
Sementes $\left(\mathrm{g} 100 \mathrm{~g}^{-1}\right)$ & 15,4 & 15,5 & 11,4 & 9,52 & 9,53 & 6,60 \\
$\mathrm{pH}$ & 5,3 & 5,6 & 5,5 & 5,1 & 5,6 & 5,5 \\
Brix & 13,5 & 13,0 & 13,8 & 12,1 & 10,0 & 13,4 \\
Acidez $\left(\mathrm{g} 100 \mathrm{~g}^{-1}\right)$ & 0,037 & 0,049 & 0,041 & 0,049 & 0,049 & 0,043 \\
Vitamina C $\left({\left.\mathrm{mg} 100 \mathrm{~g}^{-1}\right)}^{78,7}\right.$ & 107,1 & 81,3 & 70,0 & 67,1 & 75,0 \\
\hline
\end{tabular}

encontrados na literatura (Figura 2). A faixa de teores de nitrogênio considerada adequada para o mamoeiro é de 13 a $25 \mathrm{~g} \mathrm{~kg}^{-1}$, na matéria seca do pecíolo (Awada \& Long, 1971a, Awada, 1977, Awada \& Long (1978, 1980), Perez \& Childers, 1982, Perez-Lopez \& Reyes (1984) e de 45 a $55 \mathrm{~g} \mathrm{~kg}^{-1}$ na matéria seca do limbo, na fase produtiva (Prezzoti, 1992; Viégas, 1997).

$\mathrm{Na}$ amostragem de junho, os teores de $\mathrm{N}$, na matéria seca do pecíolo e do limbo, apresentaram-se mais altos que na amostragem anterior. Esse aumento seguiu o aumento da taxa de adubação efetuado a partir do mês de abril. No pecíolo, os teores de N-orgânico voltaram a cair após a amostragem de setembro, enquanto no limbo mostraram uma certa tendência de estabilização. A variação do N-orgânico no pecíolo, entre as épocas, seguiu a mesma tendência para todas as variedades enquanto no limbo houve diferença entre elas. A análise do limbo mostra que, a partir da segunda amostragem, os teores de N-orgânico apresentaram-se acima do nível crítico (Prezzoti, 1992), para todas as variedades, com exceção da cultivar "Know You" que, em dezembro, apresentou um teor de $39,3 \mathrm{~g} \mathrm{~kg}^{-1}$ e uma redução de $56 \%$ na produção em relação ao período colhido entre setembro a novembro (Tabela 2).

Alguns autores recomendam o pecíolo como parte mais apropriada para determinação do "status" de nitrogênio no mamoeiro (Awada \& Long, 1971a; Perez \& Childers, 1982). Outros, entretanto, obtiveram maior correlação entre produtividade e teor de nitrogênio no limbo (Prezzoti, 1992 e Viégas, 1997).
Os resultados deste trabalho indicam o limbo foliar como melhor indicador do "status" de N na planta que o pecíolo foliar. Os teores observados no pecíolo mostrariam a capacidade de absorção enquanto no limbo mostrariam, de fato, o aproveitamento final desse nutriente pela planta o qual difere entre as variedades.

Os teores de fósforo (Figura 3), no pecíolo de todas as variedades, encontraram-se dentro da faixa adequada de 2 a $4 \mathrm{~g} \mathrm{~kg}^{-1}$ (Awada, 1977, Awada \& Long, 1978) em todas as épocas, enquanto no limbo apenas a 'SS 72/12' apresentou, em setembro, valor abaixo da faixa de 4,5 a $5 \mathrm{~g} \mathrm{~kg}^{-1}$, indicada como adequada por Reuther \& Robinson (1986).

Aumentos nos teores de $P$, no pecíolo, foram acompanhados por reduções nos teores de N. Da mesma forma, reduções nos teores de $P$ foram acompanhadas por aumentos nos teores de $\mathrm{N}$ (Figuras 2 e 3).

Perez \& Childers (1982) observaram, também, que 0 aumento no suprimento de $\mathrm{N}$ provocou diminuição no teor de fósforo no pecíolo do mamoeiro, enquanto os dados para o limbo foram irregulares. Awada \& Long (1969) recomendam a análise do pecíolo como indicador da disponibilidade de fósforo para o mamoeiro. Os dados deste experimento mostram que os teores de $P$ no pecíolo variaram mais que os do limbo mas que diferenças entre variedades foram obtidas por meio da análise do limbo foliar.

Os teores de potássio, no pecíolo, aumentaram na amostragem de junho, após o incremento na taxa de 

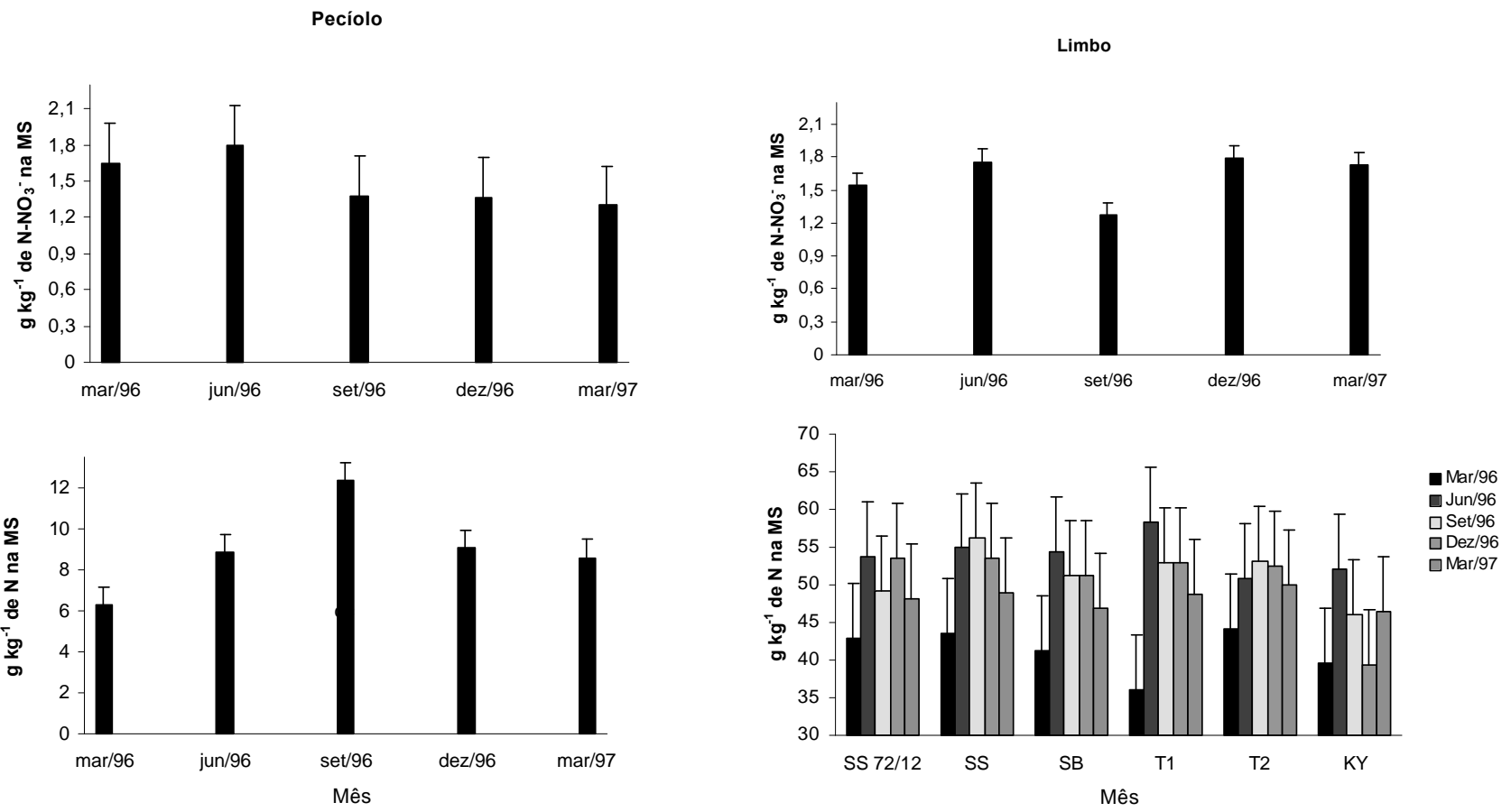

Figura 2 - Teores médios de $\mathrm{Ne} \mathrm{NO}_{3}^{-}$na matéria seca do pecíolo e limbo da folha recém-madura das variedades de mamoeiros em cinco épocas de amostragem. As barras acima das colunas representam a D.M.S. do teste Tukey a $5 \%$, para comparações entre épocas de amostragem.

adubação, e decaíram nas amostragens posteriores (Figura 3). Entretanto, a faixa adequada para o potássio, no pecíolo, situa-se entre 30 a $60 \mathrm{~g} \mathrm{~kg}^{-1}$ (Reuther \& Robinson, 1986) e, sendo assim, não foi observada deficiência de potássio pela análise do pecíolo. Por outro lado, a análise do limbo mostra que na amostragem de dezembro as variedades pertencentes ao grupo "Formosa" apresentaram teores de potássio, no limbo, ligeiramente abaixo da faixa de teores de 24,7 a $29,8 \mathrm{~g} \mathrm{~kg}^{-1}$, observadas por Costa (1995) em lavouras do Espírito Santo, consideradas de alta produtividade. Outros autores não apresentam faixas adequadas de teores de potássio para o limbo.

Os teores de cálcio no pecíolo (Figura 4) estiveram abaixo da faixa de 10 a $25 \mathrm{~g} \mathrm{~kg}^{-1}$, indicada como adequada por Reuther \& Robinson (1986), apenas na primeira época de amostragem. No entanto, os valores encontrados no limbo estão abaixo daqueles observados por Costa (1995), de 18,7 a $25,3 \mathrm{~g} \mathrm{~kg}^{-1}$ de $\mathrm{Ca}$, em todas as épocas e para todas as variedades, com exceção apenas para a Know You em março de 1997.

$\mathrm{O}$ aumento da absorção de $\mathrm{Ca}$ em função do aumento da disponibilidade de água, em decorrência da importância do fluxo de massa para o seu transporte no solo, pode ser observado quando relacionamos os dados de precipitação com os teores observados no limbo foliar (Figuras 1 e 4), não tendo sido o mesmo observado em relação ao pecíolo.

Os teores de magnésio, na maioria das épocas amostradas, apresentaram-se abaixo da faixa observada por Costa (1995) de 5,3 a $5,7 \mathrm{~g} \mathrm{~kg}^{-1}$ na matéria seca do pecíolo e de 9,2 a $12,4 \mathrm{~g} \mathrm{~kg}^{-1}$ na matéria seca do limbo (Figura 5). A tendência de variação dos teores de nutrientes para as duas partes da folha foi bastante semelhante.

Costa (1995) constatou que o $\mathrm{Mg}$ foi o segundo nutriente limitante à produção na época das chuvas em lavouras do Espírito Santo e segundo Marin et al. (1995), em solos de tabuleiros é constatada, com freqüência, a deficiência de magnésio.

Os teores de enxofre mantiveram-se dentro da faixa de 3,0 a $8,0 \mathrm{~g} \mathrm{~kg}^{-1}$, apresentada por Reuther \& Robinson (1986) como adequada para o pecíolo, e da observada por Costa (1995), de 4,8 a $4,9 \mathrm{~g} \mathrm{~kg}^{-1}$, no limbo, para todas as variedades, em todas as épocas. Nas duas partes da folha a tendência de variação entre épocas foi a mesma para esse nutriente (Figura 5).

Nas amostragens de março e setembro, os teores de boro no pecíolo (Figura 5) apresentaram-se ligeiramente abaixo do limite inferior da faixa apresentada como adequada por Reuther \& Robinson (1986), de 20 a $50 \mathrm{mg} \mathrm{kg}{ }^{-1}$. No limbo, todas as variedades apresentaram, nas três primeiras amostragens, teores de boro abaixo do valor médio de $43 \mathrm{mg} \mathrm{kg}^{-1}$ encontrado por Costa (1995), em lavouras de alta produtividade (acima de $50 t$ ha $^{-1}$ ). Entretanto, sintomas de deficiência de boro, como a exudação de látex e a deformação de frutos, não foram observados.

$\mathrm{Na}$ amostragem de dezembro foram observados os mais altos teores, nas duas partes da folha (Figura 5). Essa amostragem foi precedida pelo período de maior precipitação no ano de 1996, observado entre outubro e dezembro. 
Pecíolo
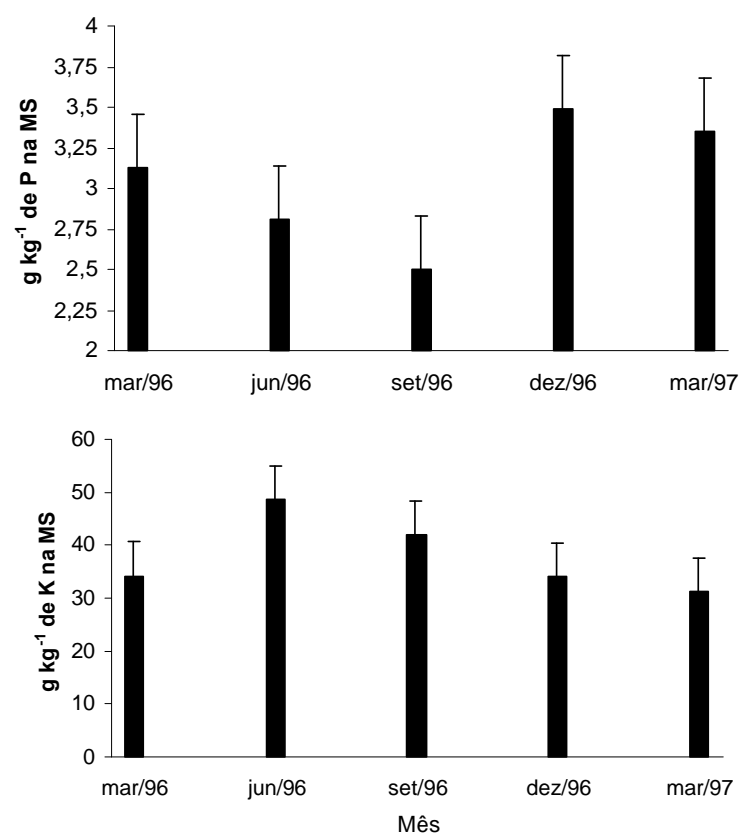

Limbo
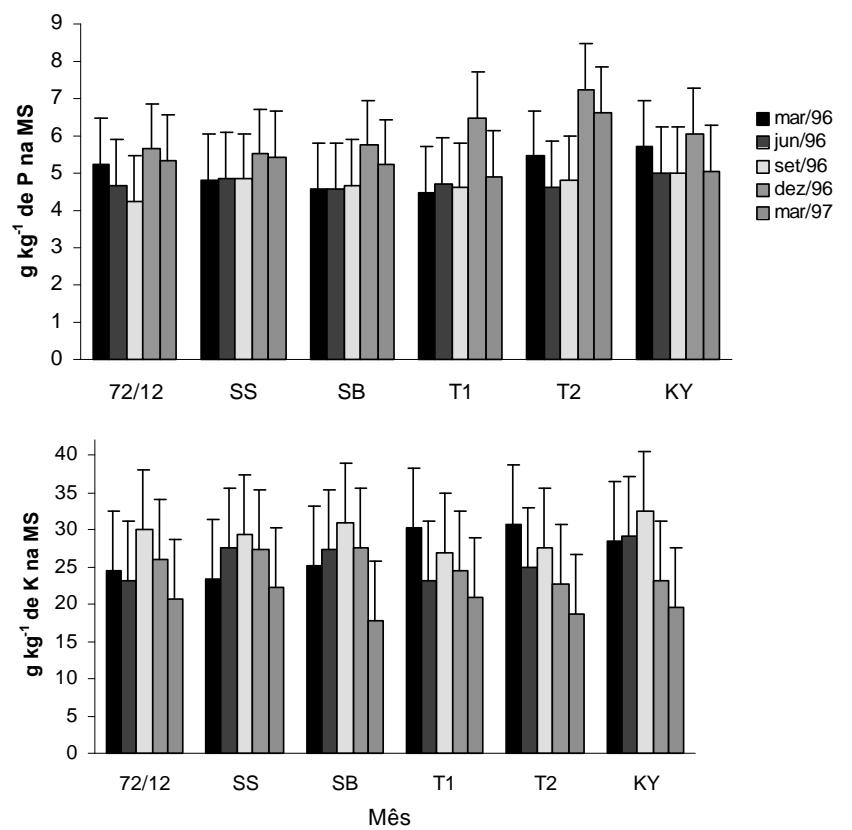

Figura 3 - Teores médios de P e K na matéria seca do pecíolo e limbo da folha recém-madura, das variedades de mamoeiros, em cinco épocas de amostragem. As barras acima das colunas representam a D.M.S. do teste Tukey a $5 \%$ para comparações entre épocas de amostragem.

Cunha \& Haag (1980) observaram redução dos teores de boro nas folhas durante o outono, um aumento no inverno e nova redução na primavera. Segundo o mesmo autor, os teores de boro diminuíram, no caule, em períodos de baixas precipitações e temperaturas amenas. Essa variação sazonal dos teores de boro pode ser explicada, em parte, pelas suas características de transporte no solo, que ocorre em maior proporção pelo fluxo de massa, sendo esse tipo de transporte influenciado pela disponibilidade de água no solo e pela taxa transpiratória da planta.

Sob condições de altas precipitações o boro é rapidamente lixiviado dos solos como $\mathrm{B}(\mathrm{OH})_{3}$. Da mesma forma, sob condições de seca a disponibilidade diminui devido ao decréscimo na mobilidade por fluxo de massa para as raízes, e polimerização do ácido bórico (Marschner, 1995). Assim, deve haver uma preocupação maior com deficiência de boro sob condições de baixa disponibilidade de água e a amostragem para monitoramento do estado nutricional não deve deixar de ser feita nessa época.

Nas amostragens de junho e setembro, os teores de cloro no pecíolo estiveram acima de $40 \mathrm{~g} \mathrm{~kg}^{-1}$ (Figura 5), valor citado por Reuther \& Robinson (1986) como nível máximo de tolerância na matéria seca do pecíolo da folha recém-madura.

Para o limbo não existe referência na literatura sobre um limite máximo aceitável para os teores de cloro. Entretanto, os valores encontrados nessa parte da folha, em todas as épocas, raramente extrapolaram $20 \mathrm{~g} \mathrm{~kg}^{-1}$ (Figura 5).
Os teores médios de cloro nas plantas situamse na faixa de 2 a $20 \mathrm{~g} \mathrm{~kg}^{-1}$ na matéria seca, o que é um valor típico de um macronutriente. Na maioria das espécies, no entanto, o requerimento para um desenvolvimento ótimo está entre 0,2 a $0,4 \mathrm{~g} \mathrm{~kg}^{-1}$, ou seja, cerca de 10 a 50 vezes menos. Uma vez que o cloro é suprido às plantas através de várias fontes (reservas do solo, água de irrigação, chuva, fertilizantes) existe uma preocupação maior acerca de sua toxicidade que de sua deficiência (Marschner, 1995).

Todas as variedades apresentaram teores de cloro mais baixos no limbo, quando comparados com os teores do pecíolo. Isso indica a existência de um mecanismo interno de exclusão ou capaz de evitar a translocação desse nutriente para o limbo, uma vez que se trata de uma parte da folha mais nobre que o pecíolo, onde ocorrem processos metabólicos vitais como a fotossíntese. Os teores de $\mathrm{Cl}$ encontrados nas várias épocas também diferiram entre as variedades. Essas duas observações mostram que a concentração de $\mathrm{Cl}$ encontrada no limbo foliar é efetivamente mais importante para a planta que a concentração encontrada no limbo e, sendo assim, deve ser utilizada no processo de diagnose.

Soares \& Quaggio (1997) recomendam que o fornecimento de potássio ao mamoeiro seja feito, preferencialmente, na forma de sulfato, provavelmente em decorrência da tendência do mamoeiro em absorver grandes quantidades de cloro, quando o suprimento é efetuado na forma de cloreto de potássio. Entretanto, não existem experimentos na literatura que comparem a forma de sulfato com a de cloreto em termos de 

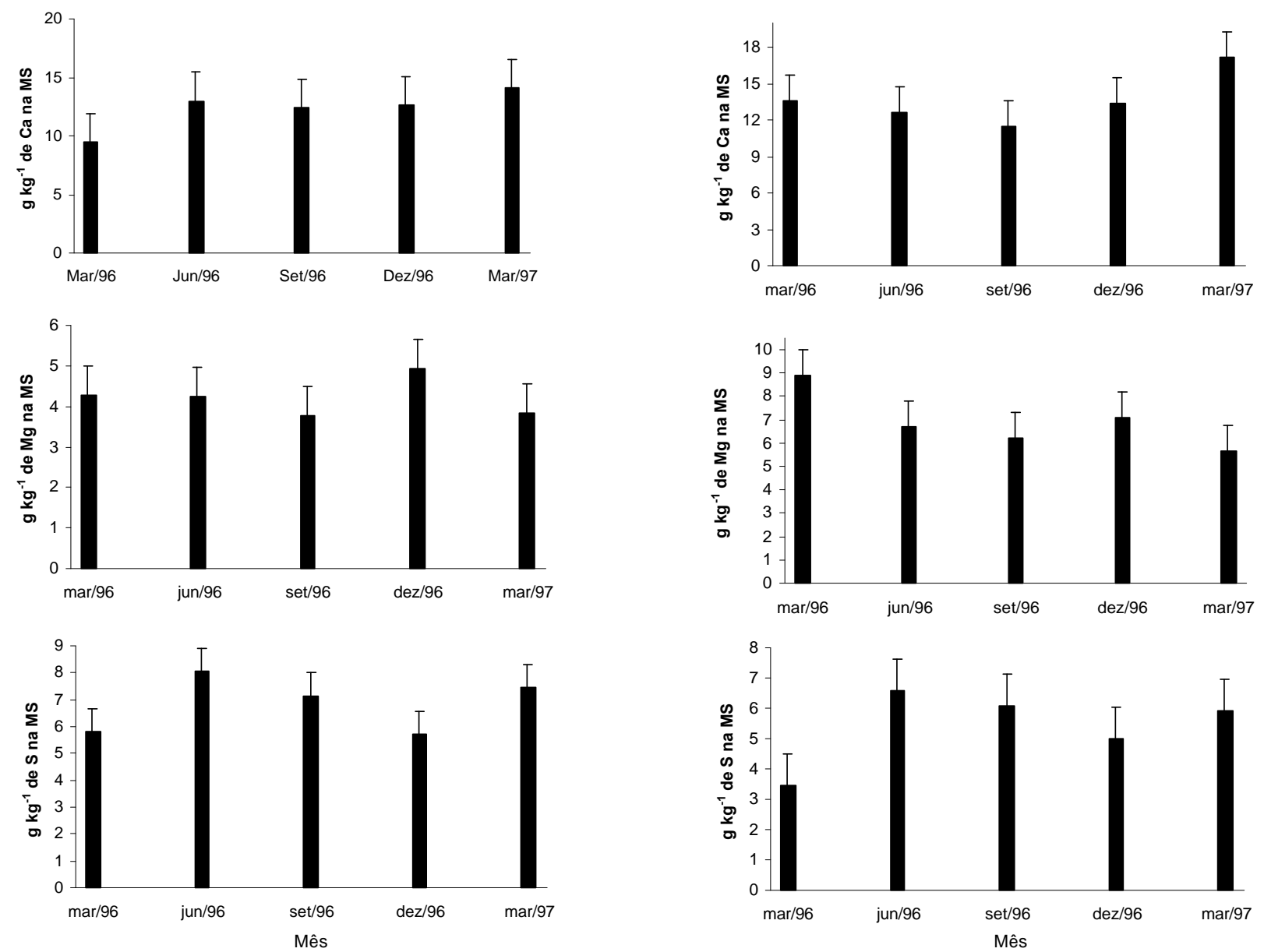

Figura 4 - Teores médios de Ca, Mg e S na matéria seca do pecíolo e limbo da folha recém-madura, das variedades de mamoeiro, em cinco épocas de amostragem. As barras acima das colunas representam a D.M.S. do teste Tukey a 5\%, para comparações entre épocas de amostragem.

produtividade e qualidade de frutos. Apesar de apresentar esses teores elevados de cloro, as plantas não apresentaram sintomas externos correlacionados à toxidez desse nutriente.

$\mathrm{Na}$ primeira época de amostragem, todas as variedades apresentaram teores de $\mathrm{Fe}$ inferiores àqueles encontrados por Costa (1995), de 114 a $142 \mathrm{mg} \mathrm{kg}^{-1}$, em lavouras de alta produtividade (Figura 5). Nas demais épocas os teores oscilaram entre as variedades, sendo que na última amostragem, as variedades do grupo "Formosa" apresentaram os mais baixos teores de ferro, situando-se abaixo da faixa de 20 a $80 \mathrm{mg} \mathrm{kg}^{-1}$ citada por Reuther \& Robinson (1986) como adequada para a cultura.

A deficiência de ferro está associada a solos alcalinos, arenosos ou a calagens excessivas. Dessas condições a única verificada no experimento foi a textura arenosa do solo. Apesar disso, não foram observados sintomas de deficiência de $\mathrm{Fe}$, como aqueles descritos por Kanan (1985) para a cultura do mamoeiro. Sendo assim, sugere-se que os teores considerados adequados para a cultura sejam melhor estudados em experimentos futuros.
Os teores de manganês mantiveram-se dentro da faixa de teores adequados nas duas partes da folha. No pecíolo, observou-se um aumento no teor de Mn, após a amostragem de março de 1996 (Figura 5), o qual pode estar relacionado ao aumento da adubação nitrogenada efetuado após essa amostragem. Awada \& Long (1980) constataram uma elevação dos teores de $\mathrm{Mn}$ e Zn como conseqüência da fertilização com N. A disponibilidade de Mn aumenta com valores mais baixos de pH (Malavolta et al., 1997). A adubação com sulfato de amônio tende a promover um abaixamento do $\mathrm{pH}$ do solo podendo, portanto, ter promovido o aumento da disponibilidade de Mn. Neste experimento, os teores de manganês no limbo, mantiveramse relativamente constantes ao longo do tempo.

Os teores de zinco no pecíolo (Figura 5) apresentaram-se dentro da faixa apresentada por Reuther \& Robinson (1986). No limbo, os valores encontrados situam-se, para todas as variedades, na maioria das épocas, abaixo daqueles observados por Costa (1995), de 30 a $38 \mathrm{mg} \mathrm{kg}^{-1}$, em lavouras do Espírito Santo (Figura 5). Nas folhas, entretanto, não foram observados sintomas de deficiência desse nutriente. 
Pecíolo
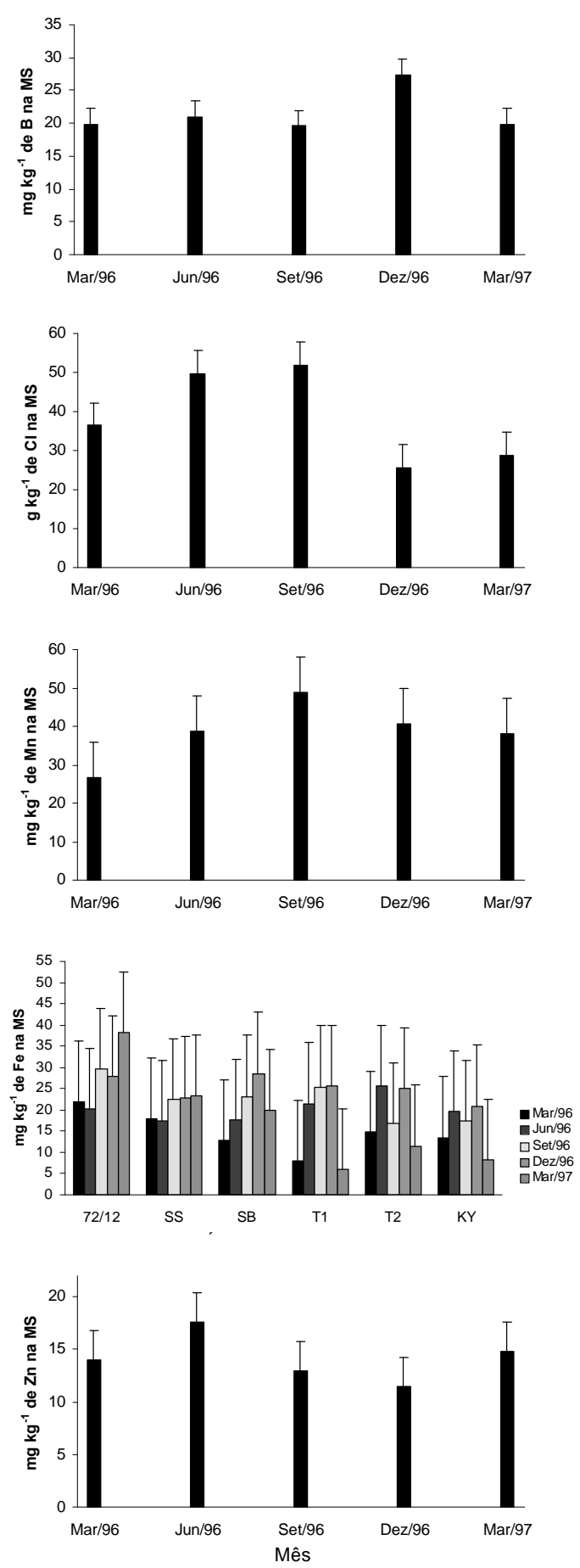

Limbo
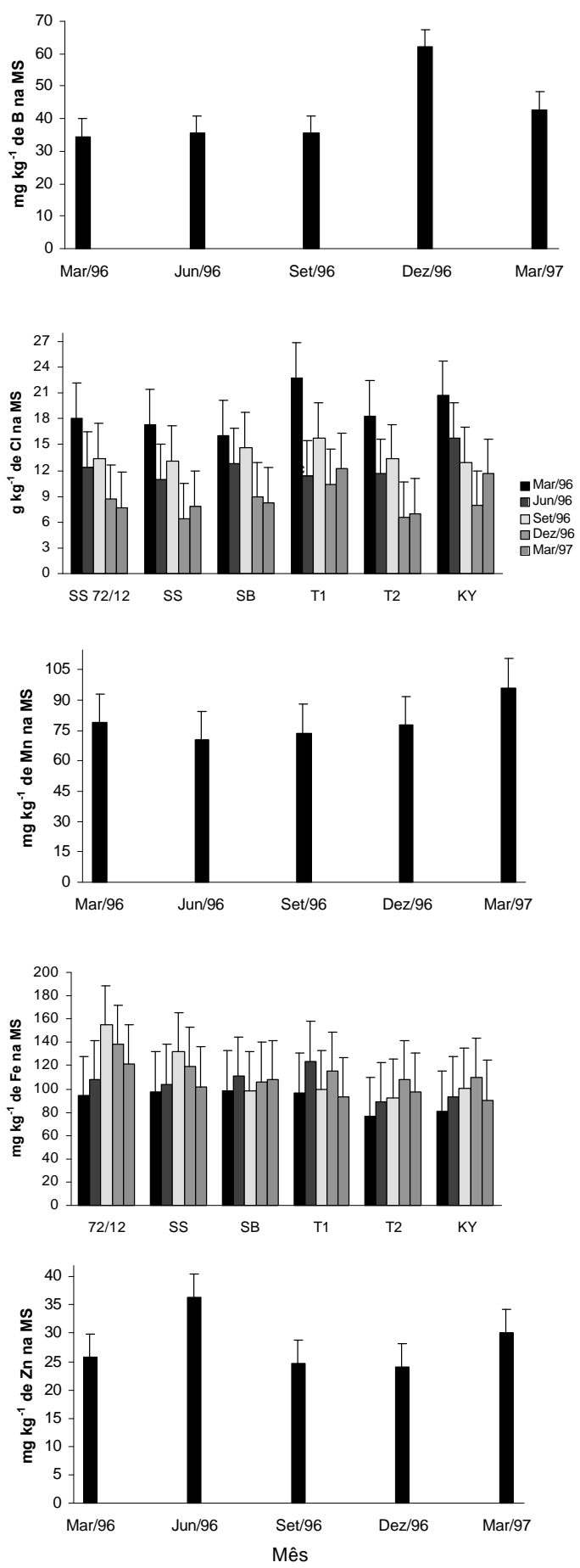

Figura 5 - Teores médios de ferro na matéria seca do pecíolo e limbo da folha recém-madura de mamoeiros dos grupos 'Solo' e "Formosa", em cincos épocas de amostragem. As barras acima das colunas representam a D.M.S. do teste Tukey a 5\%, para comparação entre épocas.

A amostragem para avaliação do estado nutricional do mamoeiro deve ser feita logo após a sexagem das plantas para evitar que a ocorrência de deficiências venha prejudicar a produção futura. Amostragens devem ser repetidas em períodos que sucedem a grandes colheitas, pois estas podem esgotar as reservas nutricionais da planta, principalmente no que concerne ao N, K e S. A interpretação dos teores encontrados deve levar em consideração que para cada nutriente existe um período mais crítico influenciado por fatores climáticos.

Para todos os micronutrientes, a exceção do cloro, observou-se tendência de acúmulo no limbo em relação ao pecíolo. 


\section{CONCLUSÕES}

A avaliação do estado nutricional do mamoeiro, quando efetuada por meio do limbo ou do pecíolo foliar leva a diagnósticos diferentes indicando a necessidade de uso de um único padrão.

A análise do limbo mostrou-se mais efetiva que - pecíolo na avaliação do estado nutricional do mamoeiro, diferenciando melhor as variedades em relação a $\mathrm{N}, \mathrm{P}, \mathrm{K}$ e $\mathrm{Cl}$, não diferindo em relação aos demais nutrientes, devendo, portanto, ser utilizada como indicadora do estado nutricional do mamoeiro.

A interpretação da análise foliar deve levar em consideração a época de amostragem uma vez que, alguns períodos são mais críticos para determinados nutrientes

\section{REFERÊNCIAS BIBLIOGRÁFICAS}

AWADA, M. The selection of the nitrogen index in papaya tissue analysis. Journal of the American Society for Horticultural Science, v.94, p.687690, 1969

AWADA, M. Relation of nitrogen and phosphorus, and potassium fertilization to nutrient composition of the petiole and growth of papaya. Journal of the American Society for Horticultural Science, v.102, p.413-418, 1977.

AWADA, M.; LONG, C.R. The selection of the phosphorus index in papaya tissue analysis. Journal of the American Society for Horticultural Science, v.94, p.501-504, 1969.

AWADA, M.; LONG, C.R. Relation of petiole nitrogen levels to nitrogen fertilization and yield of papaya. Journal of the American Society for Horticultural Science, v.96, p.745-749, 1971a.

AWADA, M.; LONG, C.R. The selection of the potassium index in papaya tissue analysis. Journal of the American Society for Horticultural Science, v.96, p.74-77, 1971b.

AWADA, M.; LONG, C.R. Relation of nitrogen and phosphorus fertilization to fruiting and petiole composition of 'Solo' papaya. Journal of the American Society for Horticultural Science, v.103, p.217-219, 1978.

AWADA, M.; LONG, C.R. Nitrogen and potassium fertilization effects on fruiting and petiole composition of 24 to 48 month old papaya plants. Journal of the American Society for Horticultural Science, v.105, p.505-507, 1980.

BENTON JONES, J.; ECK, H.V.; VOSS, R. Plant Analysis as an aid in fertilizing corn and grain sorghum. In: WESTERMAN, R.L. (Ed.) Soil testing and plant analysis. Madison: SSSA, 1990. p.521-549.

COSTA, A.N. Uso do sistema integrado de diagnose e recomendação (DRIS), na avaliação do estado nutricional do mamoeiro (Carica papaya L.) no Estado do Espírito Santo. Viçosa, 1995. 93p. Tese (Doutorado) Universidade Federal de Viçosa.
CUNHA, R.J.P.; HAAG, H.P. Nutrição mineral do mamoeiro (Carica papaya L.): V. Marcha de absorção de nutrientes em condições de campo. Anais da ESALQ, v.37, p.631-662, 1980.

EMPRESA BRASILEIRA DE PESQUISA AGROPECUÁRIA. Manual de métodos de análises de solo. Rio de Janeiro: SNLCS, 1979. n.p.

JONES JR., J.B.; WOLF, B.; MILLS, H.A. Plant analysis handbook: a practical sampling, preparation, analysis, and interpretation guide. Athens: Micro-Macro Publishing, 1991. 213p.

KANAN, S. Fe-Deficiency tolerance in papaya (Carica papaya L.). $\mathrm{pH}$ reduction and chlorosis recovery in response to stress. Journal of Plant Nutrition, v.8, p.1191-1197, 1985.

LUNA, J.V.U. Variedades de mamoeiro. Informe Agropecuário, v.12, p.14$18,1986$.

MALAVOLTA, E.; VITTI, G.C.; OLIVEIRA, S.A. de. Avaliação do estado nutricional das plantas: princípios e aplicações. 2.ed. Piracicaba: POTAFÓS, 1997. 319p.

MARIN, S.L.D.; GOMES, J.A.; SALGADO, J.S.; MARTINS, D.S.; FULLIN E.A. Recomendações para a cultura do mamoeiro dos grupos 'Solo' e 'Formosa' no Espírito Santo. 4.ed. Vitória: EMCAPA, 1995. 57p. (Circular Técnica, 3)

MARSCHNER, H. Mineral nutrition of higher plants. London: Academic Press, 1995. 889p.

PEREZ, A.; CHILDERS, N.F. Growth, yield, nutrient content and fruit quality of Carica papaya L. under controlled conditions. Nitrogen effects. Journal of Agriculture of the University of Puerto Rico, v.66, p.71-79, 1982.

PEREZ-LOPEZ, A.; REYS-R. D. Effect of nitrogen and boron aplication on Carica papaya L: II. Petiole and fruit nutrient content and $\mathrm{N}$ and $\mathrm{B}$ index for leaf tissue analysis. Journal of Agriculture of the University of Puerto Rico, v.68, p.5-17, 1984

PREZZOTI, L.C. Recomendação de calagem e adubação para o Estado do Espírito Santo: $3^{a}$ aproximação. Vitória: EMCAPA, 1992. 73p. (Circular Técnica, 12)

REUTHER, D.J.; ROBINSON, J.B. Plant analysis: An interpretation manual. Melbourne: Inkatan Press, 1986. 218p.

SOARES, N.B.; QUAGGIO J.A. Mamão In: RAIJ, B. van; CANTARELLA, H.; QUAGGIO, J.A.; FURLANI, A.M.C. (Ed.) Recomendações de adubação e calagem para o Estado de São Paulo. Campinas: Instituto Agronômico, 1997. 145p. (Boletim Técnico 100)

VIÉGAS, P.R.A. Teores de nitrogênio em tecidos foliares, produção e qualidade de frutos de mamoeiro, em função da adubação nitrogenada. Viçosa, 1997. 62p. Tese (Doutorado) - Universidade Federal de Viçosa.

WATERER, D. Petiole sap $\mathrm{NO}_{3}-\mathrm{N}$ testing as a method for monitoring nitrogen nutrition of potato crops. Canadian Journal of Plant Science, v.77, p.273278, 1997.

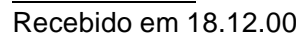

